\title{
THE ROLE OF LOCAL GOVERNMENTS IN DRIVING HIGH-QUALITY GROWTH IN THE PEOPLE'S REPUBLIC OF CHINA
}

Ehtisham Ahmad and Hans van Rijn

NO. 31

December 2020
ADB EAST ASIA WORKING PAPER SERIES 


\section{ADB East Asia Working Paper Series}

\section{The Role of Local Governments in Driving High-Quality Growth in the People's Republic of China}

Ehtisham Ahmad and Hans van Rijn

No. 31 | December 2020
Ehtisham Ahmad is a visiting professor at the London School of Economics and a Pau Yu-Kong professor at Zhejiang University, Chinese Academy of Fiscal Science, Center for Development Research, University of Bonn.

Hans van Rijn is a principal public management specialist in the Public Management, Financial Sector, and Regional Cooperation Division of East Asia Department in the Asian Development Bank (ADB).

This paper was prepared as a background study for the preparation of a high-level roundtable discussion on the transition of the People's Republic of China to high-quality development, coordinated by ADB. 
(C) 2020 Asian Development Bank

6 ADB Avenue, Mandaluyong City, 1550 Metro Manila, Philippines

Tel +6328632 4444; Fax +63286362444

www.adb.org

Some rights reserved. Published in 2020.

Printed in the Philippines

Publication Stock No. WPS200400-2

DOI: http://dx.doi.org/10.22617/WPS200400-2

The views expressed in this publication are those of the authors and do not necessarily reflect the views and policies of the Asian Development Bank (ADB) or its Board of Governors or the governments they represent.

ADB does not guarantee the accuracy of the data included in this publication and accepts no responsibility for any consequence of their use. The mention of specific companies or products of manufacturers does not imply that they are endorsed or recommended by ADB in preference to others of a similar nature that are not mentioned.

By making any designation of or reference to a particular territory or geographic area, or by using the term "country" in this document, ADB does not intend to make any judgments as to the legal or other status of any territory or area.

This work is available under the Creative Commons Attribution 3.0 IGO license (CC BY 3.0 IGO)

https://creativecommons.org/licenses/by/3.0/igo/. By using the content of this publication, you agree to be bound by the terms of this license. For attribution, translations, adaptations, and permissions, please read the provisions and terms of use at https://www.adb.org/terms-use\#openaccess.

This CC license does not apply to non-ADB copyright materials in this publication. If the material is attributed to another source, please contact the copyright owner or publisher of that source for permission to reproduce it. ADB cannot be held liable for any claims that arise as a result of your use of the material.

Please contact pubsmarketing@adb.org if you have questions or comments with respect to content, or if you wish to obtain copyright permission for your intended use that does not fall within these terms, or for permission to use the ADB logo.

Corrigenda to ADB publications may be found at http://www.adb.org/publications/corrigenda.

Notes:

In this publication, "\$" refers to the United States dollar and "CNY" to yuan.

ADB recognizes "China" as the People's Republic of China.

The ADB East Asia Working Paper Series is a forum for stimulating discussion and eliciting feedback on ongoing and recently completed research and policy studies undertaken by the East Asia Department of the Asian Development Bank (ADB) staff, consultants, or resource persons. The series deals with key economic and development problems, as well as conceptual, analytical, or methodological issues relating to project/program economic analysis, and statistical data and measurement. The series aims to enhance the knowledge on Asia's development and policy challenges; strengthen analytical rigor and quality of ADB's country partnership strategies, and its subregional and country operations; and improve the quality and availability of statistical data and development indicators for monitoring development effectiveness.

The ADB East Asia Working Paper Series is a quick-disseminating, informal publication whose titles could subsequently be revised for publication as articles in professional journals or chapters in books. The series is maintained by the East Asia Department. 


\section{CONTENTS}

FIGURES AND BOX iv

ACKNOWLEDGMENTS V v v v v

ABSTRACT

ABBREVIATIONS viii

$\begin{array}{ll}\text { I. INTRODUCTION } & 1\end{array}$

II. ANTECEDENTS: DEVELOPING NATIONAL INSTRUMENTS AND POLICIES 2

A. Background and Overview 2

B. Effects of Tax Reforms on Income Distribution and Poverty Outcomes 4

C. Effects of Tax Reforms on Fiscal Risk and Sustainability 5

III. ADDRESSING THE IMBALANCES IN SPENDING ASSIGNMENTS 7

A. Generating Better Service Delivery and Accountability 1

B. Design of Administrative and Economic Boundaries 8

IV. SUBNATIONAL FINANCING OF HIGH-QUALITY GROWTH 9

A. Introduction $\quad 9$

B. Shared Revenues 10

C. Subnational Tax Handles for Structural Change 12

D. Piggybacks or Surcharges 12

E. Property Taxes-Enhancing Equity and Generating Local Accountability 13

F. Financing and Debt Limits for Subnational Entities 14

G. Borrowing Through Local Government Finance Vehicles and Municipal Bonds 14

H. Public-Private Partnerships 15

I. Preconditions for Managing Subnational Liabilities in a Sustainable Manner 17

$\begin{array}{lr}\text { V. CONCLUSIONS } & 18\end{array}$

$\begin{array}{ll}\text { APPENDIX } & 20\end{array}$

$\begin{array}{ll}\text { REFERENCES } & 22\end{array}$ 


\section{FIGURES AND BOX}

\section{FIGURES}

1 Evolution of Tax/Gross Domestic Product Ratios and Central-Local Shares 3

2 Inter- and Intra-Provincial Migratory Flows, 2014

A.1 Differing Tendencies to Centralize Some Functions and Administration, 20 Decentralization of Others

\section{BOX}

Why Sustainable Subnational Debt Issuance Requires Own-Source Revenues 


\section{ACKNOWLEDGMENTS}

The original version of this paper was prepared by Ehtisham Ahmad, a consultant for the Asian Development Bank (ADB), as a background study for the preparation of a high-level round table discussion on the transition of the People's Republic of China (PRC) to high-quality development, coordinated by ADB. It also draws on a program of research supported by the London School of Economics/Coalition of Urban Transitions/World Resources Institute on Financing Sustainable Transitions in the PRC and Mexico (for a summary of the program, see Ahmad and Colenbrander's paper published in 2020, Financing a Sustainable and Inclusive Urban Transition in China). The paper further builds on other ADB background papers by Cameron Hepburn and Nick Stern, Minsoo Lee, Limin Wang, and Meiyan Wang. Finally, it draws on Ahmad's 2019 paper prepared for the World Bank, China: Options for Governance and Decentralization.

Valuable inputs to various drafts were provided by Benedict Bingham, Akiko Terada-Hagiwara, Xubei Luo, Meili Niu, Stefan Rau, Hans van Rijn, Andrew Reschovsky, Nick Stern, Limin Wang, Kezhou Xiao, Lin Zhu (reviewer), and by the participants at a workshop on the paper held at the ADB office in Beijing in June 2019.

The final version of the paper was prepared for publication by Hans van Rijn (principal public management specialist, Public Management, Financial Sector, and Regional Cooperation Division, East Asia Department, ADB). 


\section{ABSTRACT}

The People's Republic of China (PRC) has achieved remarkable progress over the past 25 years in terms of poverty reduction and economic growth. What makes this progress even more remarkable is that the country managed to achieve this with nascent or missing modern fiscal institutions. A second remarkable feature of the PRC's transition process is the central role that has been played by subnational governments (SNGs): in particular, in terms of providing massive public investments in physical and, to a lesser extent, social infrastructure, although revenues have been largely centralized in this period.

Progress has come at a price though, and the PRC is now at a stage where the one-sided focus on economic growth needs rebalancing, particularly in terms of addressing inequality (geographical, income, and non-income); environmental degradation; and the fiscal sustainability challenges that almost all SNGs are facing.

Despite the very rapid growth since the 1993-1994 reforms, imbalances have risen as a result of the concentration of activities and population in the coastal megacities, leading to congestion and pollution, as well as spatial inequalities. In addition, SNGs have been primarily relying on shared revenues, which have been hugely inadequate to finance the expenditure responsibilities assigned to them. Faced with these structural financing gaps, SNGs increasingly resorted to land sales and borrowing. The financing gap is estimated at $30 \%$ on average, allowing for differences across sectors. The continuing reliance on land sales for generating local revenues has led to large-scale urban sprawl, and loss of wetlands in the delta regions as well as prime agricultural lands.

This paper focuses on key fiscal aspects of these challenges. First of these is the need to reconsider current intergovernmental functional assignments for reducing risks and better provision of local services. The division of roles and responsibilities across the different tiers of government is obscured by a multitude of overlapping or conflicting laws, regulations, and guidelines, leading to blurred service delivery and administrative mandates. Disentangling these responsibilities is quite complicated and should start with an extensive legal harmonization exercise. State Council Directives 6/2018 and 8/2018 define the responsibilities of different levels of government in various functional areas.

Second is the important fiscal decentralization objective to ensure that local governments have strong and sustainable own-revenue sources, both to fund basic services that they are required to administer and to generate appropriate incentive structures and accountability, and also to anchor borrowing and access to credit. While revenue sharing and fiscal transfers will continue to be the most important sources of funding, these are not enough to put local government finances on a sustainable footing. Local governments need own-source revenues at the margin, otherwise they cannot access financing safelyincluding municipal bonds and public-private partnerships (PPPs) - without a central government guarantee.

The third aspect of these challenges is examining options for local taxation focusing on "piggyback" taxes on national personal income or carbon taxes, especially at the provincial level. This arrangement would insulate subnational spending from the volatility of revenue shares associated with adjustments in national tax rates by the central government. Importantly, it also provides the basis for the more effective operation of the subnational bond market.

Fourth key issue on promoting the fiscal sustainability of SNGs are the options for local government financing instruments, including municipal bonds (either general obligation or revenue bonds) and the use of PPPs to finance and deliver goods and services. 
As the PRC's experience shows, such local government financing is not without risk and contingent on SNG's capacity to service liabilities. This underscores the need to develop own-source revenues quickly.

Fifth and final point is the need to monitor and manage subnational liabilities carefully and to develop accurate and timely balance sheets at all levels of government, as required under the International Monetary Fund's Government Financial Statistics Manual 2001/2014 framework that has been formally adopted by the PRC.

While there has been important progress in a number of areas, critical gaps remain that need to be addressed early in the 14th Five-Year Plan period. These areas are discussed in detail through the paper but can be summarized as follows:

- The rationalization of spending responsibilities, including national social security reforms, has been initiated but lags (like it does in most transition economies).

- Tax policy reforms have been largely completed at national level, but are yet to be completed for the subnational levels of government.

- The introduction of the State Taxation Administration in the early 1990s kickstarted the tax reforms, which were more or less completed in $2015 .{ }^{*}$

- Equalization systems were initiated in 1994 at national level, but need yet to be fully rolled out at provincial level and are largely missing at subprovincial levels.

- Treasury single account was introduced in the late 1990s and is yet to be fully extended to provinces and subprovincial administrations.

- On budget, Government Financial Statistics Manual 2001/2014 frame is functioning at national level, but the requirement for full subnational balance sheets under the 2015 Budget Law is not yet fully implemented at subnational levels.

- Bond and debt markets were initiated in 2015 with support from the Asian Development Bank and the World Bank, but not yet complete as linkages with own-source revenues and balance sheet information are missing.

- Subnational debt rules and risk management have been initiated, but difficult to complete without accurate and timely balance sheet information.

The State Taxation Administration was formerly known as the State Authority on Taxation. 


\section{ABBREVIATIONS}

\begin{tabular}{|c|c|}
\hline ADB & Asian Development Bank \\
\hline $\mathrm{CCC}$ & compact, clean, and connected \\
\hline GBA & Greater Bay Area \\
\hline GFSM & Government Financial Statistics Manual \\
\hline IMF & International Monetary Fund \\
\hline LGFV & local government finance vehicle \\
\hline LSE/CUT & London School of Economics/Coalition of Urban Transitions \\
\hline NDRC & National Development and Reform Commission \\
\hline NPC & National People's Congress \\
\hline PFM & public financial management \\
\hline PIT & personal income tax \\
\hline PPP & public-private partnership \\
\hline PRC & People's Republic of China \\
\hline SEZ & special economic zone \\
\hline SNG & subnational government \\
\hline SOE & state-owned enterprise \\
\hline STA & State Taxation Administration \\
\hline TSA & treasury single account \\
\hline UDIC & Urban Development Investment Cooperation \\
\hline$V_{1}$ & value-added tax \\
\hline
\end{tabular}




\section{INTRODUCTION}

The People's Republic of China (PRC) has made remarkable progress over the past 25 years with export-led growth and poverty reduction, despite the virtual absence of modern fiscal institutions. A tax administration at the national level did not exist at the beginning of the 1990s, nor modern budget and treasury systems, although these are taken for granted in most emerging market countries.

Some of the major challenges include: (i) deepening the institutional reforms; (ii) optimizing the assignment of responsibilities in order to address high levels of inequality, congestion, and pollution in rapidly expanding metropolitan areas; and (iii) rebalancing the current overdependence on export markets, and away from the coastal megacities that also generate most of the environmental challenges.

The buildup of risks, especially at the subnational level, was exacerbated by the countercyclical policies to redress the global crisis during 2008-2010. The resulting debt overhang at the subnational level remains a significant challenge. Modernization of fiscal institutions has been underway since 1993-1994 but is far from complete. This is one of the main reasons for the PRC's continuing emerging market status.

The three pillars of the government's Medium-Term Economic Program for 2018-2021 address the main issues for the budget and inclusive growth over the medium term, and will also inform the structural reform agenda over the next decade or so (Liu 2018). Thus, policies and institutional strengthening must:

(i) address risks and liabilities that have built up in local government finances and state-owned enterprises (SOEs);

(ii) eliminate poverty during 2018-2020, and address the prevention of poverty in the medium term, with a reduction in spatial and interpersonal inequality; and

(iii) ensure a cleaner environment both to meet the PRC's commitments under the Paris Agreement and to ensure an improved quality of life for citizens.

As during the global crisis in 2008-2010, the medium-term policy imperatives in a period of uncertainty concerning directions of trade-including the financing of "clean investments"-are likely to be dictated by measures to maintain employment by rebalancing toward domestic consumption and demand, and by shifting production toward interior "production hubs." The tradeoff between different types of risk becomes extremely important, as emphasized by Liu Shangxi and Li Chengwei (Public Services Evaluation from the Perspective of Public Risk Management, in Ahmad, Niu, and Xiao 2018). In the present context, critical risks include those involving the real sector-employment and social policy-and financial and fiscal risks.

The sustainable policy agenda in the PRC has to be seen in the context of evolving institutional structures that interact with and require the use of more sophisticated policy tools and responses. The latter can be illustrated by the changing structure of the tax administration that has been made possible and is dictated by the adoption of modern tax policy instruments. These policy changes were introduced in the 1993-1994 reforms, which clearly accounted for potential political economy ramifications through a very careful balancing of "gainers" and "losers" among provinces. This has been mirrored to a lesser extent with budget and treasury institutions and policies albeit, as argued in this paper, more needs to be done to examine the interactions between tax and financing tools in particular, and between financing mechanisms and their public financial management (PFM) underpinnings. This is critical to ensure that the financing for the investments envisaged under the 14th Five-Year Plan are sustainable. 
The paper is organized as follows:

- Section II, "Antecedents-Developing National Instruments and Policies," summarizes some of the key developments to date that shaped the agenda for the investment, tax, and financing decisions to follow. It draws heavily on Ahmad, Rydge, and Stern (2013) and Ahmad (2018a).

- Section III, "Addressing the Imbalances in Spending Assignments," examines the scope for beginning the reform of spending assignments that was postponed during the 1993-1994 reforms (see Ahmad 2019). Although PFM reforms were also initiated in the late 1990s, resulting in some improvements in the budget and treasury systems at the national level, considerable work remains outstanding to strengthen subnational institutional arrangements in keeping with the PRC governance framework (Ahmad 2018b).

- Section IV, "Subnational Financing of High-Quality Growth," reviews instruments for strengthening subnational financing, while minimizing risk as outlined in the Medium-Term Economic Program. It draws extensively on Ahmad and Colenbrander's paper in 2020 (based on the London School of Economics/Coalition of Urban Transitions [LSE/CUT] research program) and outlines alternatives for own-source revenues at the provincial and lower levels. The role of "piggybacked" instruments, administered by the State Taxation Administration (STA) and legislated by the National People's Congress (NPC), protects lower levels of government from the variations in overall revenues due to national tax reductions for countercyclical fiscal policy. An increase in own-revenue sources would also anchor sustainable access to local bond systems, public-private partnerships (PPPs) and other sources of financing of public infrastructure by the private sector. Finally, the section summarizes ongoing work on city-level taxes and revenue-raising mechanisms (Ahmad et al. 2020) to supplement the revenue-sharing arrangements that are currently in place.

The final section highlights the preconditions to facilitate a more significant role for the private sector, drawing on the literature and experiences to manage subnational liabilities in a sustainable manner.

To put the PRC's experience in a wider context, the appendix provides a brief overview of specific international experiences with (fiscal) decentralization and local government reform.

\section{ANTECEDENTS: DEVELOPING NATIONAL INSTRUMENTS AND POLICIES}

\section{A. Background and Overview}

By the early 1990s, the PRC introduced tax reforms to consolidate the structural changes introduced by the Fiscal Responsibility System initiated in the early 1980s, and to redress the collapse in government revenues (Ahmad, Rydge, and Stern 2013) (Figure 1). Given the difficulties with rationalizing spending responsibilities, the PRC authorities rejected the standard prescription to first address spending responsibilities and turn subsequently to the tax assignments in the "finance follows function" model popular with international agencies. Thus, spending responsibilities remained at an extremely decentralized level, including for typical national functions like pensions and unemployment insurance.

From the perspective of this paper, two features stand out:

- Tax institutions were weak or nonexistent. A central tax administrative capability was created from scratch in the early 1990s to administer a "rudimentary" value-added tax (VAT) and other shared revenue bases. 
Figure 1: Evolution of Tax/Gross Domestic Product Ratios and Central-Local Shares

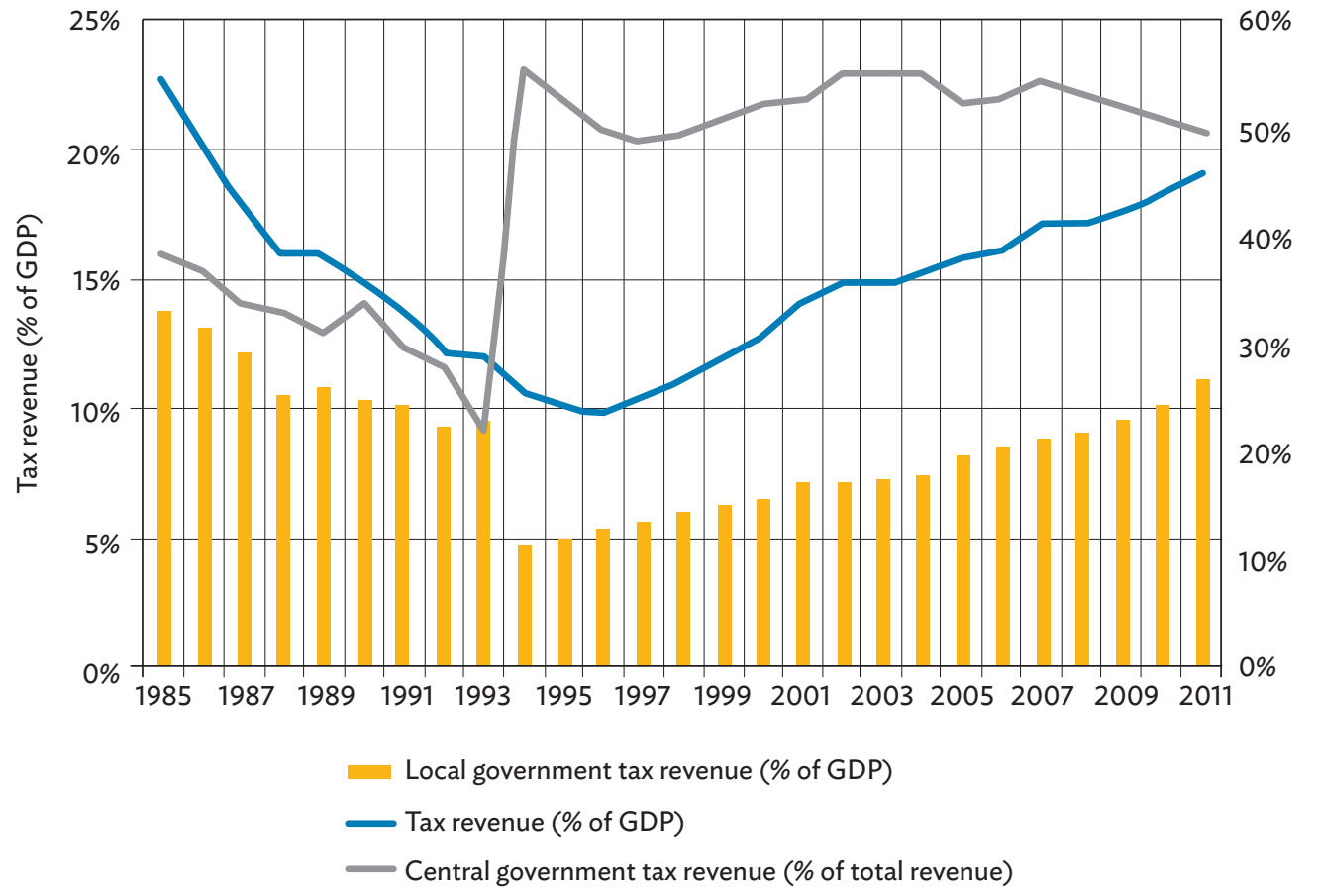

GDP = gross domestic product.

Source: Ahmad, E., J. Rydge, and N. Stern. 2013. Structural Change Leads to Tax Reforms Leads to Structural Change. LSE Asia Research Center and China Development Forum. Beijing. March 2013.

The VAT introduced was of the "importers and producers" variety: taxes on capital purchases were not offset against VAT on sales. This potentially discriminated against exporters and was one of the reasons that the establishment of special economic zones (SEZs) at the time became important.

- A solution. A political economy solution was needed to implement the tax reform, which replaced more distortive local taxes: (i) a "stop-loss provision" was introduced guaranteeing provinces pre1993 levels of revenues; (ii) an origin-basis sharing arrangement was needed to persuade more advanced provinces to participate; and (iii) an advanced equalization system was introduced to be phased in over time, to the advantage of the poorer provinces. Most importantly, a revenue-returned system provided additional funds to the coastal provinces, and greatly helped in the creation of the export hubs that have fueled the spectacular growth performance since then.

The major consequence of the gradual recentralization on the revenue side (Ahmad et al. 2002) -with the extreme spending decentralization - was that budgetary pressures opened up for all local governments. As the shared revenues tend to stick at the provincial/capital city level, deficits are telescoped downward toward the lowest tiers that also have the weakest monitoring capabilities (Xiao 2018). But since most of the essential social spending is at the city and/or township level-including most of the schools and primary care clinics and health facilities, and key measures to address environmental degradation and pollution-fiscal and financial risks easily translate into social risks, as emphasized by Liu Shangxi and Li Chengwei (in Ahmad, Niu, and Xiao 2018). 
Under the 1993 Budget Law, local governments were not permitted to borrow but could set up special financing vehicles, such as local government finance vehicles (LGFVs), using urban development investment corporations (UDICs). With imperfect monitoring of the "off-budget" operations of the UDICs, these LGFVs tended to become "slush funds" to circumvent central government strictures or oversight.

Another consequence of the process was the increased reliance of local governments on land sales to finance basic infrastructure. With gains highly concentrated around the developing coastal megacities, this process led to huge urban sprawl and loss of prime agricultural land. Lease proceeds tended to be held in off-budget accounts and added to the rent seeking as well as interpersonal inequalities (Wang, $\mathrm{Wu}$, and Ye [2018] present an excellent survey of the drawbacks).

In 2017, there was a clampdown on local government land sales and land value capture - patterned after Hong Kong, China-to address the adverse impact on the environment as well as the buildup of local liabilities including through PPPs. However, following the countercyclical fiscal policy to offset potential trade shocks in 2019, there has been a resumption of land sales, as shared revenues were affected by the cuts to the main national tax heads (VAT and income taxes) that are also shared with local governments and provide the major share of subnational revenues. Also, the effective borrowing constraints have been relaxed, adding to the risks that are already large and not fully captured in the budget data. More recently, important metropolitan areas, such as Shenzhen, have frozen the Hong Kong, China-style land sales to developers, making it imperative to move quickly to an alternative and more robust financing mechanism. It should be noted that modern valuation-based taxes apply to property sales and business properties - but the bulk of the almost $2 \%$ of the gross domestic product is generated through land sales.

Although there has been a discussion of a traditional (United States-style) recurrent property tax in the PRC, and experiments in Shanghai and Chongqing were applied to property owners and the market values of properties, the results were not particularly encouraging. This had a knock-on effect on the prospects for a potential property tax to anchor a municipal bond system. Consequently, the adoption of municipal bonds or PPPs have not yet achieved the potential benefits that might be expected as part of a sustainable development strategy. However, the potential remains for very useful financial deepening tools that should reduce local risks and generate greater accountability for local investment decisions. For sustainability, such borrowing needs to be dovetailed with a subnational own-source taxation agenda.

\section{B. Effects of Tax Reforms on Income Distribution and Poverty Outcomes}

Given the limited infrastructure connectivity in the interior of the PRC at the time, the 1993-1994 reforms led to the consolidation and expansion of coastal hubs. With the relatively low, albeit fairly equally distributed individual incomes in the 1980s, an increase in income dispersion was a consequence of the growth process, and a driving factor for the migration to the coastal hubs (Ahmad and Wang 1991). Also, relatively low-income levels in the early days meant that the scope for rebalancing from investment and exports to domestic consumption was fairly limited. While the strategy of coastal hubs supported by revenue returns was criticized by some of the PRC's development partners as likely to generate spatial inequalities, it was the only feasible mechanism to maintain double-digit growth over 2 decades, and to provide employment opportunities for over 150 million coastal migrants, released from agriculture and low value-added activities in the interior of the country. In addition, over 750 million people were taken out of poverty in just over 2 decades (the bulk of the global total poverty reduction during this period) driven by the strategy of developing the coastal hubs.'

E. Ahmad. 2018. Rebalancing in China: Fiscal Policies for Sustainable Growth. The Singapore Economic Review (SER), World Scientific Publishing Co. Pte. Ltd., vol. 63(04). September. 
However, widening disparities in personal and spatial incomes pose problems for the long-term sustainability of the PRC development strategy. As pointed out in Zhang (2016), the increase in the level of inequality has been particularly high - the Gini coefficient rising from around 0.4 in 1992 to around 0.52 in 2013 . This is now at levels reached in the most unequal of market-based emerging economies in Latin America, such as Chile, where reduced complexity due to a reliance on primary commodity exports has limited employment opportunities. Given the implicit social contract in the PRC, high levels of inequality combined with unemployment are likely to be unsustainable in political economy terms.

Increasing interpersonal inequality is also a function of a tax system that is still evolving, with a personal income tax (PIT) that is likely inequality-enhancing. This is because it is based largely on withholding from formal wages and tends to miss out rapidly increasing nonwage incomes. Together with the absence of effective taxation of assets, particularly property, the net effect is likely to be inequality-enhancing.

\section{Effects of Tax Reforms on Fiscal Risk and Sustainability}

As discussed further, local governments lack the ability to adjust rates (even within centrally specified bands), and thus do not have own-source revenues. This affects sustainable access to credit at local levels. It also limits the operation of a fairly sophisticated equalization system that in principle should permit city- and county-level governments to provide similar levels of public services at similar levels of revenue effort.

It is important to note that shared revenues are not own-source, in the sense of local governments exercising a significant subnational control over the revenues generated, either over rates at the margin or administration, as defined earlier. This is because the recipient jurisdiction is not able to increase the revenues if needed at a particular point in time, as would be the case to repay debts and liabilities. This is true even if the revenue shares are untied, and in this sense are like transfers. The logic underlying this proposition is briefly outlined (Box).

In 2015, the local business tax was absorbed into the VAT, completing the VAT reforms with the integration of the base on services and goods. This was primarily driven by the desire to reduce the cost of doing business and rationalize the export regime, and also to create an integrated level playing field. It is interesting that after the VAT integration it was possible to remove the borders around a major SEZ, Shenzhen, as full export refunds became available regardless of the location of the firm. This was a critical move in laying the foundations of closer linkages with neighboring cities, and in creating the kernel for the Greater Bay Area (GBA).

An added advantage of the integration of the business tax with the VAT was that full information becomes available on the value chain. Thus, the interactions with the income and excise and/or carbon taxes are clearer, also potentially reducing cheating in such taxes.

While revenues were expected to fall as a result of the VAT integration, given the effects of crediting or offsets due to the VAT on service sector inputs, overall revenues actually increased. The better information available to the tax administration made it harder for firms to evade taxes by disguising activity levels, wage bill, or profits.

The biggest drawback of the integration of the business tax into the VAT in 2015 was the loss of the last major revenue base in the hands of the local governments. While aggregate revenue losses for subnational governments (SNGs) were largely prevented by changes in the sharing proportions, as pointed out by Xiao (2018), the budgetary pressures increased at the lowest tiers of the administration, as higher levels struggled to meet mandates and pushed spending responsibilities downward. This adversely affected 
local service delivery capabilities in tier 3 or tier 4 cities where they are needed most. The absence of own-source revenues at the lower-level jurisdictions adds to risk and makes it more difficult for them to access and manage credit or longer-term liabilities. This clearly adds bias toward the large metropolitan areas and/or capital cities, making it more difficult to pivot toward the sustainable goal of compact, clean, and connected (CCC) cities.

\section{Box: Why Sustainable Subnational Debt Issuance Requires Own-Source Revenues}

The issue of subnational debt sustainability has been subject to a great deal of debate. The "debt brake" due to be implemented in Germany in 2016 imposes a zero-borrowing limit on the lender as they have no own-source revenues (Chen, Cui, He, Milbradt 2017). Some argue that a "golden rule" might be more appropriate-and this would be the equivalent of the special bond issuance for investment purposes in the People's Republic of China (PRC). But the golden rule is hard to define precisely, and it is seldom the case that project-related bonds or public-private partnerships (PPPs) will avert recourse to the budget. This was seen in Spain in 2008 and the Mexican road financing disaster during the tequila crisis of the 1990s illustrating what can go wrong. The problem is magnified exponentially with weak subnational public financial management and incomplete information that generate soft-budget constraints. And in the PRC (post1993 and post-1994), local government financial vehicles were meant to follow a golden rule but also became a major source of risk. The argument can be summarized as follows:

Start with the "Simonsen rule" for debt sustainability. For national governments, this links changes in liabilities to changes in revenue-raising potential

$$
\partial L=f(\partial R)
$$

where,

$$
\partial R=\partial t \partial B
$$

where $t$ is the set of tax instruments and $B$ is the base. The Simonsen rule then translates into the relationship between the interest rate and the growth rate of the economy driving the revenue base in the medium term. For subnational governments (s), the subnational $R_{s}$ can be decomposed into

$$
t_{s} B_{s}+\rho B_{n}
$$

where $t_{s}$ is own-source taxes in relation to a subnational tax base $B_{s}$ and is the share of national taxes meant to cover assigned spending $E_{s}$. In the PRC intergovernmental settlement post-1993/1994, the revenue shares were meant to cover a set of agreed expenditures given the effective centralization of revenue bases, and to close the resulting vertical gap. Thus, there is not much flexibility in reality.

Thus, in the PRC provinces, $t_{s}=0$, and $\rho b_{n}-E_{s}=0$, even if the share of national revenues is untied, so the first difference of available revenues is zero. Consequently, without own-source revenues, the sustainable level of subnational debt in the PRC is zero (regardless of the type of the local bond issuance).

The even greater earmarking that has emerged from the current "decentralization" effort further reduces the ability of the local governments to meet debt liabilities and finance basic public services. Consequently, the incentives for local government are to continue to incur debt, especially through special instruments and PPPs that are not so easy to monitor, significantly adding to overall risk. While these pressures are seen, in the London School of Economics/Coalition of Urban Transitions case studies, in the metropolitan regions (Guangzhou), capital city clusters (Nanchang), the most severe effects are on the tier 3 and/or tier 4 cities (such as Jieshou) that could prevent them from becoming clean, compact, and connected sustainable "hubs."

Source: Ahmad, E. 2019. China: Options for Governance and Decentralization. For the World Bank and Chinese Academy of Fiscal Science. Beijing. 


\section{ADDRESSING THE IMBALANCES IN SPENDING ASSIGNMENTS}

\section{A. Generating Better Service Delivery and Accountability}

Almost 25 years after the 1993-1994 reforms, the PRC has moved to address spending assignments. Imbalances in the intergovernmental assignments accentuated following the 2015 absorption of the business tax into the VAT. This was reflected in the telescoping of deficits downward, and in the gaps in service delivery standards between capital cities and other interior smaller towns. To some extent, the focus on countrywide standards on poverty, income distribution, and exposure to deteriorating environment are concerns that form part of the medium-term economic priorities enunciated in 2017. The attempts to clarify responsibilities of lower levels of government have followed, and preliminary decisions have been taken, including the centralization of social security arrangements and all tax administration.

Given the increasing imbalances between spending responsibilities and available financing, the State Council has begun to clarify the responsibilities of different levels of government in various functional areas (State Council Directives 6/2018 and 8/2018). While this is a very welcome initiative, considerable work is needed to take the process forward in a coordinated manner without completely undermining the initiatives at the local level that have been so important in supporting the strong growth performance over the past 25 years. This is because the disentangling of spending responsibilities can very quickly turn into unfunded mandates unless there is a corresponding reassignment of own-source revenues over which the local jurisdictions have some control at the margin. It is important to signal again that ownsource revenues are needed to underpin or unlock access to credit needed to finance capital spending.

One of the assignments that is most detached with international practice relates to social security financing in the PRC (for retirement and unemployment benefits), which is done is done through local pool arrangements. With the one-child policy in place for an extended period, the old agedependency ratios increased sharply, particularly in the coastal regions. Initially, the concern was that deficits along the richer coastal funds should not be met by surpluses in the funds held in the poorer interior provinces (given a younger demographic profile). However, the situation has changed with the migrations from the interior to the coastal provinces, and the western or interior province funds have come under stress, whereas the pension pools for those along the coast, e.g., in Guangdong, remain relatively healthy. It is thus appropriate that the government has decided to centralize the local funds, benefits, and contributions, as is the case in most advanced countries. Even then, with the sharp aging of the population, the pension pools are expected to run dry by 2035. Cutting employers' contributions to bolster employment prospects - both as a way to gradually increase retirement age, and also to form part of countercyclical fiscal policy, will, however, increase the short-term pressures on a "Pay-As-YouGo" national pension system.

Greater clarity on the functional responsibility of SNGs for spending assignments should also provide a basis to delineate the size and functions of new urban jurisdictions. In some cases, the infrastructure and linkages provide clarity on the size and institutional design for new urban areas. The expectation is that the focus will shift to smaller cities (perhaps at tier 3 or below), with better service delivery, less congestion or pollution and improved employment prospects. The possible assignment of own-source tax instruments, along with the more carefully defined spending arrangements, and access to credit for local infrastructure will all play a role in determining the new boundaries of sustainable cities. 
The option of horizontal cooperation across cities/provincial boundaries to achieve common objectives does not even work well, even in the United States, where the liabilities are known with a reasonable amount of certainty. The difficulties in four jurisdictions managing and financing the "orphaned" Washington Area Transport Area that runs the metro system has led to inadequate financing of operations and maintenance spending and deteriorating quality of services. In the Chinese context, it is likely that game-play will result across cities with opaque accumulation of liabilities and no clear ownsource revenues, and would rule out any significant horizontal cooperation. Enforced transfers from richer to poorer jurisdictions would likely be seen as ad hoc adjustments to a scientific and arms' length intergovernmental transfer and equalization framework, envisaged as part of the 1993/1994 reforms, and discourage efficient operations in both rich and poorer provinces.

The PRC already has experience in creating a new administrative structure by amalgamating cities-as with the three cities (Wuchang, Hankou, and Hanyang) that were merged into Wuhan in the 1920s. However, it should be pointed out that attempts to change administrative and political jurisdictions to better reflect economic responsibilities have not been very easy to implement in Europe-and only Denmark has managed to carry out any significant restructuring. Appropriately designed tax handles turn out to be key in this regard-and much depends on rate setting capabilities at the margin rather than just the administration.

\section{B. Design of Administrative and Economic Boundaries}

Any sustainable urban transition strategy in the PRC will require building on new "employment hubs" and value chains and would likely be designed to minimize the impact on employment from the potential disruption to global trading patterns, and to establish CCC cities in the interior as argued in Ahmad and Colenbrander (2020) report on LSE/CUT Program on Financing Sustainable Urban Transitions. This is in line with the long-standing objectives to "rebalance" from exports to domestic consumption and from the mega-coastal cities to CCC cities.

Given a joint focus on innovation as well as sustainable hubs, among the more interesting issues is the integration of the SEZs (such as Shenzhen) into the rest of the economy. The key is to build on the spatial linkages with other cities in the supply chains, particularly in the high-tech corridors as in the GBA. The completion of the 1993-1994 tax reforms was critical in defining the preconditions for increased connectivity and linkages, as it enabled the removal of barriers around SEZs to enhance connectivity, as was the case around Shenzhen SEZ following the 2015 reform.

Similarly, the Belt and Road Initiative will open up spatial equalization possibilities in the poorer Western and Southern provinces that were previously elusive, even with respect to the Western Development Strategy from the turn of the century (Ahmad, Neuweg, and Stern 2018). This will operate through changing relative prices and value chains with the easier and shorter distances (especially in time) to markets in Europe, the Middle East, and Africa. In fact, this has already begun to affect private sector investment decisions: the "hub" of Horgos on the border of Kazakhstan, for example, is largely financed by private Jiangsu firms. Again, these new hubs will eventually require new administrative arrangements, including the establishment of own-source revenues and other fiscal institutions, to better finance the infrastructure required to build on the enhancement in connectivity due to the Belt and Road Initiative.

The key structural element of the high-quality growth strategy requires a transformation of the urban and city landscape in the PRC. The city and subnational levels of government will have to take greater responsibility for the stated policy outcomes. Given the size and diversity of the PRC, a number of institutional arrangements that could be considered include: 
(i) New central city cluster arrangements that will create linkages with the surrounding cities and rural areas to generate CCC economic zones.

(ii) The shift to clean activities and services in the large metropolitan areas and tier 1 cities such as Beijing, Shanghai, and Guangzhou.

(iii) The generation of innovative high-tech hubs, for instance the Silicon Valley underpinnings of the GBA proposal and specialized high-tech zones elsewhere (e.g., in the Yangtze River Delta area).

(iv) The development of new "hubs" in smaller tier 3 and/or tier 4 cities. These include some in the Western region, given the changing relative cost structures and value chains with the Belt and Road Initiative.

The governance criteria for new urban structures such as the GBA could involve the redrawing of administrative boundaries. This will affect responsibilities for local infrastructure and public services as well as financing arrangements, as emphasized in the preceding sections.

The typical instruments used to involve the private sector in managing and financing public infrastructure, including PPPs and local government bonds, have so far had mixed success in the PRC, as the absence of own-source revenues has exacerbated the risks associated with these instruments. The use of these instruments by "responsible" tiers of government again depends on the availability of adequate "ownsource" tax handles, as well as full information on the liabilities generated on the balance sheets of the respective jurisdictions.

Moreover, the existing debt overhang from the countercyclical policies during the 2008-2010 global crisis may exacerbate risks, unless steps are taken to strengthen local governments' tax and governance preconditions for managing local debt. The balance between the efficiency and financing perspectives versus the prudential management of risks at each level of administration needs to be carefully assessed as part of the urban transformation agenda.

Although the PRC has adopted the International Monetary Fund's (IMF) Government Financial Statistics Manual (GFSM) 2001/2014 standard, and the Ministry of Finance also now requires accrual accounting under the 2015 Budget Law revision, the development of balance sheets at the county/city level will involve a great deal of work, even in the more advanced areas of the country (Ahmad and Zhang 2018). The clear delineation of risks and liabilities, using full balance sheet information would be a precondition for a more efficient access to credit, including local bonds, as well as effective management of PPPs.

\section{SUBNATIONAL FINANCING OF HIGH-QUALITY GROWTH}

\section{A. Introduction}

One of the consequences of the coastal hubs strategy and the huge expansion of megacities along the eastern region of the PRC has been an increase in emissions and deterioration in the air quality. Likewise, increasing urban sprawl has led to congestion and increasing costs. And, as mentioned above, both spatial and interpersonal inequalities have increased significantly with a rise in the Gini coefficient from approximately 0.4 to 0.52 in 2013 (Zhang 2016).

Although an equalization system, based on standardized spending needs and revenue potential was introduced in 1994, this only operates for current spending. The absence of effective own-source 
revenues limits the effectiveness of the equalization framework that applies not just to the spending cost differential but equally to the dispersion of the revenue base. Moreover, within provinces, equalization is much more problematic, as transfers and shared revenues tend to stick at the higher levels, and budget pressures trigger the telescoping down of spending responsibilities to lower levels.

Disparities in income and employment generation potentials are better responded to through capital spending, particularly on connectivity infrastructure and generation of new "productive hubs." Indeed, this is at the heart of the attempts to rebalance the structure of production and consumption over the past decade or more. It is instructive to see the experiences of Guangdong and Zhejiang, two of the most developed provinces, with probably the best connectivity infrastructure in the country, but with very high within-province inequality. Indeed, the Gini coefficient for Guangdong is as high as for the whole PRC (Ahmad, Niu, and Xiao 2018).

The continuing disparities, even in the more developed provinces, reflect imbalances in the spending and revenue assignments and in effective service delivery. These have an impact on the incentives facing the private sector to invest in the less well-developed cities and lower wage areas, and for qualified workers to remain in these areas. The telescoping of budget pressures for Guangdong (Xiao 2018) indicated large disparities in public service provision, as well as liabilities across the province. Similarly, an assessment of spending needs within Zhejiang suggests very large disparities in expenditure needs (Reschovsky and Yan 2018) across counties in the PRC's richest provinces. This is largely driven by the large variance in social security requirements as well as transport, and a fundamental cause of this relates to the absence of an own-source revenue anchor to also guide the incentive structures facing officials.

It is thus not surprising that the direction of migratory flows is still strongly toward the tier 1 coastal cities (Figure 2, and Luo and Zhu, forthcoming), particularly for better-educated migrants, and this applies to both across-province migration as well as within-province population flows. This pattern is more pronounced for the more educated and skilled workers. But there is some evidence of migration of highincome people to smaller cities and/or villages in the vicinity of the metropolitan areas attracted by lower pollution and facilitated by e-commerce and transport linkages.

The LSE/CUT program case studies included Guangzhou (a metropolitan city), Nanchang (representing a capital city cluster), and Jieshou (a well-connected but poorer tier 3-4 level city, which was, however, designated as a science park). All cities were highly indebted, but the pressures were greatest on Jieshou (Ahmad and Colenbrander 2020). These very brief patterns suggest that the rebalancing to CCC cities will require considerable work on making the smaller and more compact cities attractive to investors and workers alike. This involves, as discussed below, greater accountability for infrastructure and social services that needs to be generated and financed in a sustainable manner. Local access to own-source taxes is the key driver in this regard.

\section{B. Shared Revenues}

SNGs have relied increasingly on shared revenues and intergovernmental transfers to close vertical gaps since the systemic tax reforms since 1993/1994 resulted in an increasing centralization of the revenue structure and administration. As indicated earlier, the revenue sharing was an integral part of the political economy dynamics in the PRC that led to the local governments accepting a recentralization of taxing powers to grow the aggregate revenue pie. But each upward shift in tax assignments has been accompanied by changing revenue shares, to the extent that now most local governments rely almost exclusively on shared revenues, which often does not trickle down sufficiently from provincial capitals given their own budget constraints and spending needs. And as pointed out earlier, the fiscal arrangements have not prevented an increase in inequalities across provinces, but also within the richest provinces (Ahmad, Niu, and Xiao 2018). 
Figure 2: Inter- and Intra-Provincial Migratory Flows, 2014

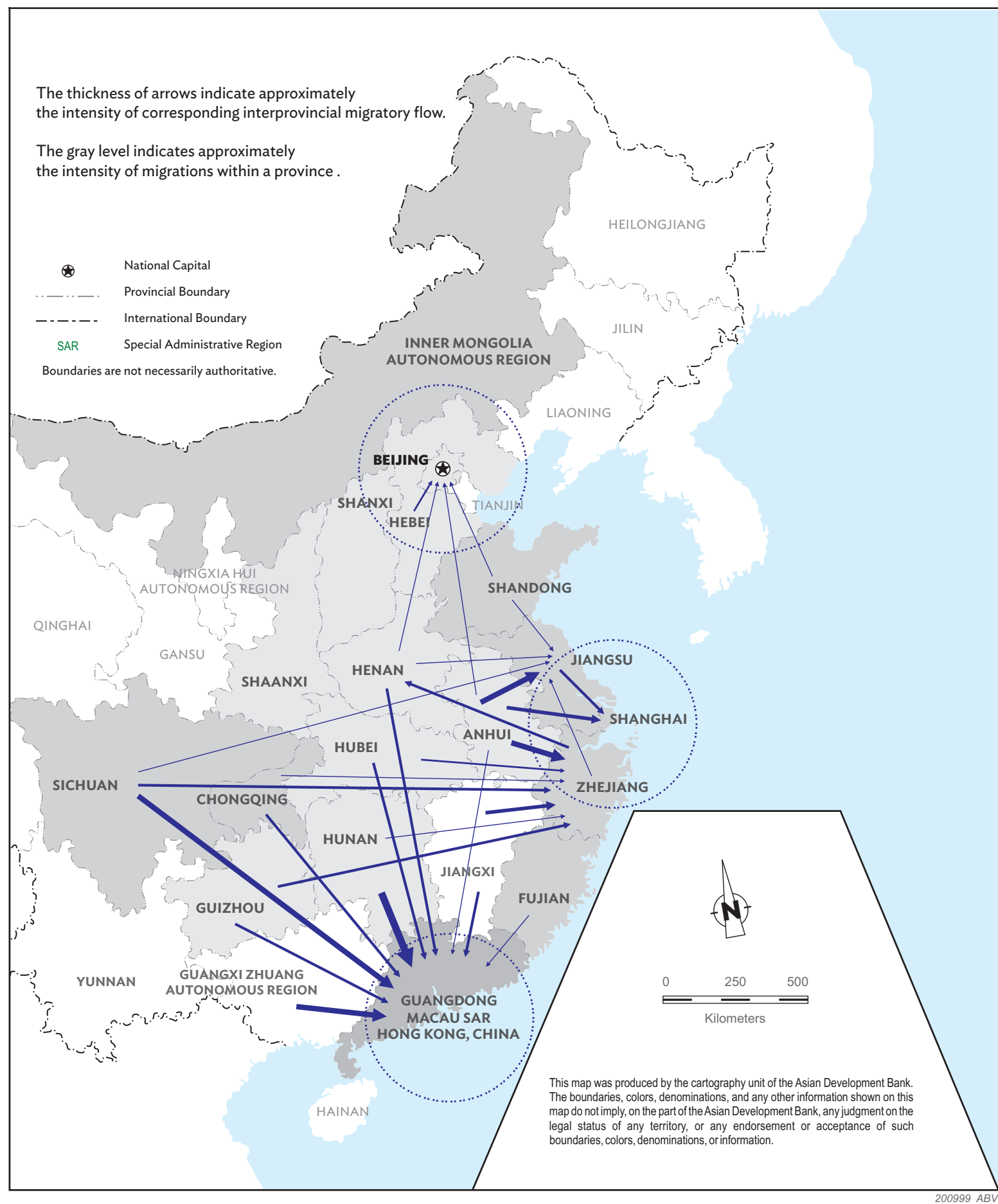

Source: Luo, X. and N. Zhu. Forthcoming. Spatial Mobility and Regional Structural Transformation in China. LSE/CUT/WRI Program on Financing Sustainable Urban Transitions in China and Mexico. 
There are, in addition, two main difficulties with an intergovernmental system exclusively financed by revenue-sharing arrangements:

(i) Increased vulnerability of subnational operations to macroeconomic shocks. Central governments often have to cut taxes for countercyclical fiscal policy purposes, and this has happened during 2019 to offset the slowing of the economy, and to forestall the effects of potential trade shocks. But fluctuating shared revenues are particularly damaging to local governments that are responsible for critical basic services, such as education, which cannot be cut or adjusted at short notice.

(ii) Shared revenues are no replacement for own-source revenues, even when untied. This is because the essence of own-source revenues is that the relevant subnational jurisdiction can increase the rate in order to meet additional spending, say to cover liabilities. Shared revenues cannot be increased by the relevant SNG, and in this sense, shared revenues are very much like intergovernmental transfers.

\section{Subnational Tax Handles for Structural Change}

Own-source revenues - or instruments over which a jurisdiction can exert control at the margin-are critical in determining the effectiveness of "responsible" subnational levels of government, and determine the extent to which private resources can be leveraged without increasing risk. This does not imply that the administration has to be local (Ahmad 2015), and national tax reforms of policy and administration can provide for own-source revenues through piggybacks or surcharges, although not on all taxes.

In unitary states, legislative power is typically held by Parliament; in the PRC, the NPC performs that role. It is sufficient for economic sustainability and to count as own-source revenue, if the NPC were to set a band within which local governments would have a choice to set their marginal rates. Indeed, this is currently the case with some property transfer taxes (Ahmad et al. 2020). Note that this can work even if the tax administration has been centralized, as now in the PRC. It is not problematic for local accountability if the STA were to carry out the main administrative functional responsibilities and the local government were to set a surcharge or piggyback on the national base. This is enough to ensure local accountability and sustainable access to credit. Local administration is not needed for this purpose.

\section{Piggybacks or Surcharges}

The recent centralization of all tax administration in the STA is sensible and does not preclude accountability for subnational levels of government. The piggybacks or surcharges could be useful in achieving distributional and environmental objectives, besides providing own-source revenues that affect the incentives facing local officials. It is important to note that:

- The piggyback would protect local budgets from the effects of central government measures to adjust the overall tax rates for macroeconomic purposes.

- It could open the way for sustainable access to financing through bonds and PPPs without exacerbating local risks.

Piggyback options that might be relevant for the PRC include taxes on the following bases: (i) personal income tax (PIT) and (ii) carbon tax. 
A piggyback on the PIT is important from the perspective of interpersonal equity, and also to convert a shared revenue into an own-source revenue of equivalent amount that can be used to leverage sustainable access to financing and credit, such as a local government bond system. This comes about through the better utilization of information on assets that typically exists at the local levelthe principal instrument in this regard is a property tax, although vehicle registration and use taxes also provide additional information.

However, as rich people tend to live in more developed neighborhoods, the piggyback on the PIT could provide more revenues to richer jurisdictions, thereby increasing spatial inequalities in service delivery potential. The piggyback is typically used in tandem with a fiscal equalization framework.

The PRC already operates a fairly sophisticated fiscal equalization system. This links standardized spending needs to fiscal capacities. But, as there are no effective own-source revenues at the present time, in reality it only depends on standardized spending needs, and consequently loses the incentive effects of the linkage with own-source revenues. Also, there is a significant gap at the subnational level.

Without effective own-source revenues, it is hard for the central government to hold a lower level accountable for assigned functions. This is because equalization funds are untied (even though they reflect demographic and cost differentials) and local governments are then able to use transfers and local revenues to more efficiently address local preferences. Alternative performance-based and earmarked transfers are very difficult to implement without fairly sophisticated monitoring mechanisms, which at present are not effectively implemented.

A local piggyback on a national carbon tax would not only provide an own-source revenue base, it could also generate incentives to reduce carbon emissions in the most polluted areas. This is because a piggyback would permit setting a higher marginal rate in the more polluted areas. The national base, or minimum, is important to prevent a race to the bottom. As with a piggyback on the PIT, the carbon tax can be implemented easily by STA in excise mode. A carbon tax would have to be carefully modeled, keeping in mind the effects on different groups of households and potential compensatory mechanisms that might be considered if necessary. However, as the objective of a carbon tax is to change behavior, directly linked compensatory measures, although frequently recommended by international financial institutions, should be sparingly used.

\section{E. Property Taxes-Enhancing Equity and Generating Local Accountability}

Many PRC local governments have relied on land sales and combinations of PPPs to finance infrastructure. The early success of this alternative to a local tax system together with access to credit, needs to be tempered with the potential downside relating to urban sprawl, loss of prime agricultural land, and offbudget accounts that might spawn rent-seeking behavior..

It will be important to carefully delineate the scope of the land sale and value-capture alternatives in the future-especially as the speculative motives in the interior may not be as strong as in the tier 1 cities along the coast. Particularly important are new options for recurrent property taxation at the local level to put city-level finances on a more stable foundation. These newer property tax options will open up opportunities for tax increment financing and betterment levies.

As in most emerging market economies (and the United Kingdom), a United States-style property tax (based on ownership and valuation) has not had much success in experimentation in the PRC. Variants experimented in Shanghai and Chongqing were not very successful-largely because of relatively complex ownership and leasehold patterns and difficulties with valuations. There is typically a stronger market for commercial property, where the traditional property tax should apply. 
An alternative for residential property (Ahmad, Brosio and Pöschl 2015; Ahmad, Brosio, and Gerbrandy 2018; A hmad et al. 2020) could be a simple tax on size, location, and occupancy, linked to local service delivery. The tax-benefit linkage would diffuse political resistance and also lead to greater accountability for local service delivery.

A simple area-linked tax on occupancy could also provide an interesting alternative for migrant informal sector workers. The payment could be used to also provide a mechanism to ensure access to local public services. This would provide support for some of the most vulnerable urban groups in the PRC.

In the PRC, the tax-benefit linkage would diffuse political resistance and also lead to greater accountability for the clearer responsibilities envisaged under State Council Resolution 8/2018. As seen in a recent simulation based on a six-city survey (Ahmad et al. 2020), housing-education subsidy to migrants reduces inequality significantly in most cities. An education subsidy to all children would also reduce inequality, albeit somewhat less than the previous simulation, but may be politically more attractive.

The valuation-based taxation of business properties, and all sales including of residential properties, would be maintained as the current system is well designed, even if it does not raise much revenue. A surcharge or additional stamp duties could be imposed on properties above a specific value for both revenue and distributional purposes.

Vehicle taxes, user charges, and regulatory mechanisms also provide additional typical local instruments, and with the local beneficial property tax form the set of revenue-related financing instruments that could lead to more sustainable cities.

However, care should be taken to eliminate "nuisance fees and taxes" that add to the cost of doing business as a "beneficial property tax" is introduced. This is an important element in improving the business climate.

\section{F. Financing and Debt Limits for Subnational Entities}

With one of the highest levels of decentralized and/or deconcentrated structures of spending responsibilities in the world, no own-source revenues, and relative weak monitoring of spending and liabilities at the lower levels of administration, there has been a spiraling of subnational borrowing and liabilities. While the aggregate debt levels for general government are well within prudential limits given the resources of the central government, the telescoping downward of deficits and liabilities poses heightened risks particularly at the subnational level and increases at the lowest levels (Ahmad, Niu, and Xiao 2018).

The determination of the sustainable overall resource envelope for general government over the medium term, and apportionment of debt limits across lower levels of government, are critical for the financing of new "employment generation hubs" without a buildup of risk. Key elements will be the determination of own-source tax handles for "responsible" levels of government that will be permitted access to capital markets to finance relevant local- and/or city-level infrastructure, and full information on the liabilities generated.

\section{G. Borrowing Through Local Government Finance Vehicles and Municipal Bonds}

While the Budget Law (prior to 2015) did not permit local governments to borrow, companies established by urban development investment corporations (UDICs) and special local government 
finance vehicles (LGFVs) could do so. The expectation was that the UDICs would largely follow an implicit "golden rule" and would borrow for investment. This instrument, however, began to be misused by local governments in the absence of full information on local operations, and began to be discouraged. But as it happens, the LGFVs were again used to implement the CNY4 trillion bank loan financed stimulus in 2009, and contributed to the debt overhang at the present time, and the pressure to resort to nonbank financing as repayment pressures mounted (Chen, He, and Liu 2017 for a summary). In particular, municipal corporate bonds and trust loans expanded as repayment pressures mounted and bank loans and municipal bonds plateaued. It is interesting that "shadow banking" and wealth-managed products increased rapidly in financing municipal corporate bonds.

The 2015 Budget Law permitted approved local governments to issue bonds but did not link this to own-source revenues. Qualifying criteria were set in terms of local revenue shares, and other city and/or municipal income. These have been revised up to CNY30 billion and CNY300 billion, respectively. However, sustainability should be defined in terms of own-source revenues for the reasons discussed earlier, as the ability to increase revenues is typically needed to repay incremental liabilities. As it is, total explicit debt of CNY16.8 trillion is very close to the formal limit of CNY18.7 trillion.

\section{H. Public-Private Partnerships}

PPPs can be an effective risk-sharing mechanism between the state and a private partner. This also permits efficiency gains through the utilization of private expertise. The major drawback is that there is asymmetric information on the investments, management and effort put in by the private partner and the local government, and between local governments and the center. Complex contracting arrangements involving equity participation by the private partner, and recourse mechanisms are needed to avoid incentives to renege by the private partner and the local government.

The literature often assumes that when the private party is a state-owned enterprise (SOE), it will largely remain transparent. However, in the PRC case, where the SOE is owned by a local government facing a soft budget constraint, there is a temptation for some local governments to "hide liabilities" off-budget, including in the SOEs, mirroring the experience of the LGFVs. Such problems, particularly with utilities, were observed in an assessment of County K in Jiangsu (Ahmad and Zhang 2018).

A case where PPPs are not appropriate is in the case of uncertainty, as indeed with climate change. Under these circumstances, an "unbundling of contracts" along the different stages of the product life cycle could be appropriate (Bhattacharya et al. 2017). In general, unbundling loses the efficiency aspects of the PPP process, and also runs the danger of privatizing the profits, but socializing the costs. The rapidly growing literature that builds on developments in contract theory and practical examples of PPP failures is summarized in Ahmad, Vinella, and Xiao (2018) for the G24, and in practical lessons including preconditions drawn in the LSE/CUT paper on upscaling investment (Ahmad et al. 2019).

A key requirement to manage the liabilities generated by PPPs is to require that these be placed on the balance sheets of the relevant governments with appropriate provisioning. Not following this principle has been very problematic in Europe as there is an incentive for local governments to use PPPs to "kick the can down the road," as part of "gameplay" with the center. Also, asymmetric information between the private party and the government, and between different levels of government, can lead to renegotiation of terms and higher incidence of liabilities than contracted. ${ }^{2}$

2 E. Ahmad. 2018. Governance Models and Policy Framework: Some Chinese Perspectives. Journal of Chinese Governance. Volume 3 (Issue 2). 
The PRC was one of the first countries to adopt the standards of IMF's GFSM 2001/2014 framework. The full balance sheets at all levels of government are an integral component of the GFSM, although the PRC initially operated at a modified cash basis at the central and provincial levels, and the required shift to accruals did not come until the 2015 Budget Law. It is, however, very difficult to set up the GFSM 2014 framework in lower-level administrations, and to ensure proper coverage of general government operations. Although there has been good progress in setting up national and provincial treasury single accounts (TSAs), considerable work is needed to operate local balance sheets, and supporting government integrated financial information management systems. This was seen in the gaps in the balance sheets in an advanced country in Jiangsu province (Ahmad and Zhang 2018). New technological advances, particularly using blockchain technology, can considerably simplify the budget and revenue circuits, and there may be a case for integrated financial information management system provisions at the provincial levels for subprovincial operations. This is an area for further work.

Unfortunately, the absence of full and accurate balance sheets at the local government levels means that estimates of "implicit" liabilities will involve a fair degree of guess work. Estimates of implicit debt including guarantees, SOE liabilities, and PPPs suggest that this is around CNY20 trillion, or greater than the explicit debt figures. More systematic estimates of "hidden debt" by the National Audit Office for six cities was put at CNY15.4 billion for these cities, and Shaoyang city accounted for CNY7.2 billion in this sample. Self-assessments by cities are being encouraged by the Ministry of Finance, and Hefei has declared CNY47.6 billion and Huangnan CNY2.4 trillion.

After a period of resurgence of PPPs as part of both the fiscal stimulus post-2013, and as a financing mechanism associated with the Belt and Road Initiative, the National Development and Reform Commission (NDRC) paused in 2018 to assess the repayment capabilities for PPPs by local governments. Of extant PPPs, 2,000 projects were stopped. The second quarter 2018 evaluation eliminated 856 projects involving CNY956.9 billion. Interestingly, one of the projects stopped was the CNY30 billion Batou metro-suspended in August 2017-and requests for financing metro systems in 43 other cities were put on hold.

Given the existing subnational debt overhang, the weakly developed local tax system, and the risks involved with another 2009-type stimulus, NDRC in August 2018 initiated a carefully targeted expansion. This was directed at the northeast rust belt, and Jilin's capital city, Changchun. As mentioned earlier, Jilin is one of the provinces losing workers. NDRC authorized the construction of a light rail system of 135 kilometers, with a bond issuance for CNY78.7 billion ( $\$ 11.4$ billion) on 10 August 2018. Recognizing that Changchun would not be able to handle the financing costs of the bond issuance, this will be met by the central government.

This innovative investment decision is directed at ensuring a cleaner and more efficient city in the future, making it more attractive for both workers and private investors, and is entirely in line with the mediumterm objective of minimizing risks, and using investments for both income distribution purposes as well as to ensure a cleaner environment. Of course, this investment supplements the more traditional mechanisms of countercyclical policy with the easing of reserve requirements.

The Changchun example shows that it is important to clearly specify that the liabilities should be on the balance sheet of the central government, as the city administration is acting as an agent of the central government, with the responsibility clearly not on its budget or balance sheet. The alternative is to put it on the local government balance sheet along with a central government guarantee.

The same issue applies with the issuance of municipal bonds for countercyclical purposes and liabilities not being placed on the local government balance sheet. These must be correctly accounted for, either on the central government's balance sheet, or those of the local government with central guarantees. Not doing so runs the risk of further weakening the municipal bond market system. 


\section{Preconditions for Managing Subnational Liabilities in a Sustainable Manner}

Subnational fiscal rules, while can be helpful in many cases, are not credible without adequate ownsource revenues and full information on the time profile of the liabilities. Thus, to anchor both the municipal bond system and the use of the PPPs, there needs to be:

(i) A rapid movement toward a system of subnational piggybacked taxes, or the beneficial property tax that can be implemented fairly rapidly.

(ii) Full information on the liabilities generated placed on the relevant government's balance sheet, and if necessary, with guarantees for countercyclical purposes.

In the context of budget systems reforms, the PRC has been rolling out the GFSM 2001/2014 framework since it was first introduced in 2001 at the national level. This system was initially managed on a cash basis and gradually rolled out at the provincial level. Implementation at the county and municipal levels remains patchy. It was not until the change in the Budget Law in 2015 that accrual accounting was introduced. Consequently, significant work is needed to generate full information on liabilities within local balance sheets for the benefit of markets and investors (Ahmad and Zhang 2018). The process becomes complicated with the emphasis on PPPs. While the involvement of the private sector is an important step in financing public investments, this must be managed carefully (footnote 2 ).

Treasury systems in the PRC were modernized at the same time as the introduction of the GFSM 2001/2014 framework, with the establishment of a nested system of TSAs for the central and provincial governments. Again, this is a critical reform made feasible using modern banking and clearing mechanisms, as well as (eventually) electronic payments and receipts. This way, all cash flows in the economy can be tracked, minimizing the possibilities for diversion of funds.

With the disentanglement of spending responsibilities, full GFSM 2001/2014, as well as a TSA, a central government should be able to establish more detailed targets for local officials and be able to monitor outcomes on a real-time basis, as is being attempted for example in Zhejiang. However, a meaningful analysis would also apply to arrears, and the buildup of liabilities. Thus, it should be possible to ensure compliance by local governments of (potential) fiscal responsibility targets in their jurisdictions, as well as monitoring of the effectiveness of service delivery if full balance sheets were available.

In the interim, without full information on all sources of debt, the incentives remain for local officials to meet the detailed spending targets through the buildup of liabilities. Although the PRC had moved toward the GFSM 2001/2014 format almost 10 years ago, together with a system of TSAs, local operations are mainly managed on a cash basis, and liabilities are not recorded effectively in the budget and treasury systems, or in local balance sheets. As argued in Ahmad and Zhang (2018), recording full information on liabilities in the local level balance sheets, while desirable, will take many years to become fully operational. Thus, it may not be appropriate to rely too much on performance targets without full balance sheets.

Without the full information, consistent with GFSM 2001/2014 and International Public Sector Accounting Standards (and this will take time to generate), it is not evident that the local governments or their companies would be able to service their debt sustainably without having to pass it on to Beijing. Nor would they have an incentive to manage their liabilities without a significant own-source revenue instrument. Clearly, the Chinese central government has the capability to handle local debt easily, but it would create a moral hazard and weaken the budget constraints if it were to do so on a regular basis. 
The National Audit Office tool used to approximate the magnitude and risks involved in local government debt, while important to maintain, takes just too long for macroeconomic management of the economy. As stressed in Ahmad and Zhang (2018), with certain assumptions it should be possible to triangulate incipient local debt problems by creating an early warning system based on the People's Bank of China monetary survey and credit issuance to local governments. This can then be supplemented by targeted audits by the National Audit Office.

For the sustainable hubs, some preconditions must be met. It should be possible to ensure transparency mechanisms on a pilot basis, so that there is complete information for sustainable access to credit, but linked to an assessment of local own-source revenues to ensure sustainability. Thus, both the balance sheet data and the own-tax revenues would need to be kept at the level of the relevant institutional structure.

\section{CONCLUSIONS}

Financing a high-quality development strategy in the PRC will need to reflect the medium-term economic strategy of the government: minimize risks, address extreme poverty and income distribution, and generate a clean environment.

Implementation will be closely linked to the focus on clean cities and sustainable hubs. Key elements will be the determination of own-source tax handles for "responsible" levels of government that will be permitted access to capital markets to finance relevant local/city level infrastructure, and full information on the liabilities generated.

The tax system is a key driver of structural change-first, by directly influencing incentives facing firms and households, and at the subnational level, financing basic services; and second, indirectly, by anchoring access to credit for local infrastructure. With the centralization of tax administration and policy in the PRC, the central government has a critical role to play in relation to overall national tax design, as well as subnational tax design options.

Thus:

(i) National tax policies and administration can be adapted for local governments, particularly in relation to possible piggybacks on the PIT and a carbon tax.

(ii) The piggybacks protect local government revenue assignments better than shared revenues for equivalent revenue assignments, as the piggyback does not vary with adjustments in central tax rates.

(iii) The piggybacks can also be the basis for access to credit, and as the local government can adjust the marginal rate within a band, can be used to underwrite municipal bonds.

At the local level:

(iv) A simple recurrent property tax based on occupancy and size and/or location of property, linked to local services, can provide own-source revenues for cities and replace land sales, and also an anchor for sustainable access to credit for local infrastructure. 
In reality, property will be subject to a set of different taxes. Ahmad et al. (2019) pointed out that the simplified location-and/or area-based tax on residential properties would continue to be supplemented by:

(i) a valuation-based tax on property sales (with a surcharge on very expensive properties), and

(ii) an ownership-valuation based tax which business properties should continue to be subjected to, as there are typically more transactions than for households, and the same political economy considerations do not apply.

This makes it possible to apply betterment levies, a much more efficient mechanism for financing local infrastructure than land sales; and VAT would apply to first sales, to reduce the construction costs for businesses and to provide information on profits and wages in the construction sector.

The combination of taxes makes it possible to ensure that the property tax system also reflects and supports the infrastructure needs at the local level without resorting to land sales. One of the most important aspects of a property tax is that it could provide a basis for accessing credit for financing local infrastructure. This includes local government bonds, as well as liabilities under PPPs, without adding to the risk currently inherent in subnational operations.

In addition, full information on liabilities generated and access to local own-source revenues are preconditions for sustainable access to borrowing and credit and PPPs, and an apportionment of the sustainable overall resource envelope over the medium term across lower levels of government will be critical for the new "hubs." 


\section{APPENDIX}

\section{The Debate on Decentralization versus Centralization: Putting the People's Republic of China in International Perspective}

Even in market economies, there are opposing tendencies regarding decentralization and centralization for a number of functions. The strongest arguments for the former are in relation to meeting local preferences and accountability of local officials or elected officials for clearly defined functions, and the subsidiarity principle has evolved in the European Union to push down responsibilities to the lowest level possible for effective provision.

Accountability in electoral systems comes through electoral discipline or "yardstick competition," where voters punish nonperformance by their elected representatives. In administrative systems with appointed officials, both the definition of spending responsibility and outcome criteria are needed, along with the establishment of hard-budget constraints (i.e., officials are not able to meet targets by running up liabilities or debt).

The centralization tendencies, on the other hand, are typically in relation to income distribution and minimum standards, externalities including the environment, and risk management. These tendencies are summarized in Figure A.1.

Figure A.1: Differing Tendencies to Centralize Some Functions and Administration, Decentralization of Others
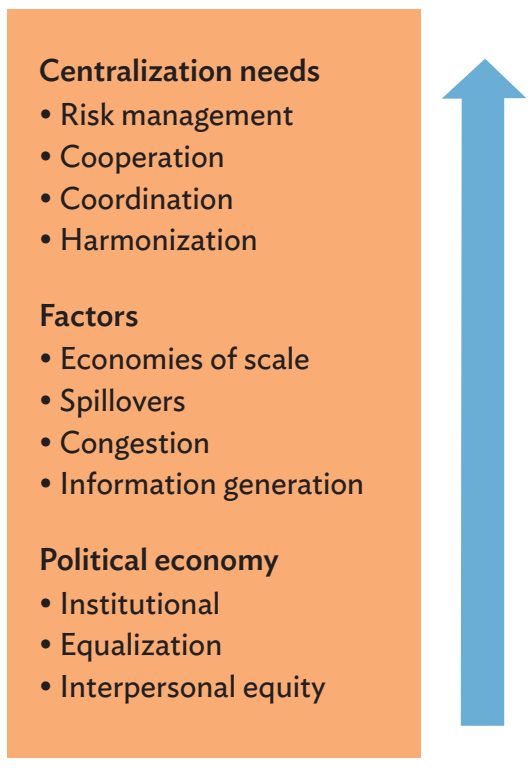

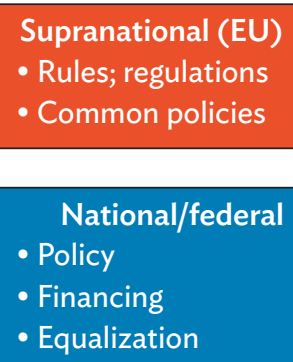

Supranational (EU)

- Rules; regulations

- Common policies

National/federal

- Policy

- Financing

- Equalization

Provincial

- Financing at margin

- Accountability

\begin{tabular}{|l|}
\hline Local \\
- Own source revenues \\
for financing at margin \\
- Sustainable cities and \\
"hubs" for growth and \\
employment
\end{tabular}

Decentralization

- Devolution

- Participatory democracy

- Control

- Accountability and effective provision

Political economy

- Yardstick competition

$\mathrm{EU}=$ European Union.

Source: Ahmad, E. 2015. Governance and Institutions. In E. Ahmad and G. Brosio, eds. Handbook of Multilevel Finance. Cheltenham: Edward Elgar. 
A typical problem arises when local officials or elected officials choose not to provide or meet minimum standards, say for education, either because they lack the financing or have other priorities.

It is important to keep in mind that there are three components to any spending assignment. These include (i) policy decisions (e.g., coverage of years of education) or goals concerning literacy standards; (ii) actual implementation (e.g., who is responsible for running of schools, and hiring and monitoring of teachers; and (iii) financing arrangements.

There is a tension between these aspects in most large multilevel countries with different assignments depending on political and institutional choices. We illustrate the difficulties with respect to primary education.

In the United States' governance model with electoral competition across jurisdictions, basic education is typically a local government function that involved local decision-making, financing, and monitoring choices. This is also consistent with the subsidiarity principle that requires functions to be managed at the lowest feasible level. However, education generates huge externalities for high-quality growth in the long run:

(i) Nigeria and Pakistan assigned education to lower levels of government in constitutional amendments, and in neither case was adequate financing assured. In Nigeria, municipalities refused to pay the teachers and the function had to be reassigned upward. In Pakistan, unfunded mandates have resulted along with a continuation of falling standards.

(ii) Centralization of education in Mexico involved financing arrangements with administration at local levels. However, there are problems of ensuring that monies are spent as designed effectively at the local level, and only in $\mathbf{2 0 1 4}$ did the federal government try to find out who the teachers were on the central payroll, albeit not very successfully. It is not reasonable to expect that the federal and/or central government would be able to directly manage a primary school system in large multilevel countries. Given the importance of education for long-term growth prospects for the country as a whole, a number of Latin American countries have instituted "earmarks" for key functions, such as education.

The difficulty with earmarks is that they put a lot more emphasis on the ability to separately track special purpose spending for the recipient administration (received from higher levels) relative to spending out of local budgets for local priorities. Thus, for example, primary education is often assigned to the lowest tier of government. Yet, given the importance of the assignment, central financing is often involved-for example, in Mexico and Bolivia. In Mexico, the central financing was for the vast majority of teachers, often hired by state or local governments in parallel with some hired out-of-state and/or subnational funds. With earmarks, the education spending financed from a central special purpose transfer would need to be shown separately from spending out of local funds.

Another alternative is to fully decentralize the function and then track outcomes. This still requires a balance sheet. And since education is a key function of government, it is important to ensure that all jurisdictions have the ability to provide a similar level of service with a similar level of tax effort. But the incentive systems inherent in equalization transfer systems, however, require clarity in assignments as well as own-source revenues. 


\section{REFERENCES}

Ahmad, E. and Y. Wang. 1991. Inequality and Poverty in China: Institutional Change and Public Policy 1978-1987. World Bank Economic Review. 5 (2). pp. 231-257.

Ahmad, E. et al. 2002. Recentralization in China? (October 2002). IMF Working Paper. IMF: Washington, DC.

Ahmad, E., J. Rydge, and N. Stern. 2013. Structural Change Leads to Tax Reforms Leads to Structural Change. LSE Asia Research Center and China Development Forum. Beijing. March 2013.

Ahmad, E. 2015. Governance and Institutions. In E. Ahmad and G. Brosio, eds. Handbook of Multilevel Finance. Cheltenham: Edward Elgar.

Ahmad, E., G. Brosio, and C. Pöschl. 2015. Local Property Taxes and Benefits in Developing CountriesOvercoming Political Resistance? In E. Ahmad and G. Brosio, eds. Handbook of Multilevel Finance. Cheltenham: Edward Elgar.

Ahmad, E., G. Brosio, and J. Gerbrandy. 2018. Property Taxation - Economic features, Revenue Potential, and Administrative Issues in a Development Context. European Commission Project FED/2016/380/048. Luxembourg: Publications Office of the European Union.

Ahmad, E., M. Niu, and K. Xiao. 2018. Fiscal Policies for Sustainable Development in China-Rebalancing in Guangdong. New York: Springer.

Ahmad, E. and X. Zhang. 2018. Towards Monitoring and Managing Sub-National Liabilities in China: Lessons from the Balance Sheet of County K. In E. Ahmad, M. Niu, and K. Xiao, eds. Fiscal Policies for Sustainable Development in China-Rebalancing in Guangdong. New York: Springer.

Ahmad, E., A. Vinella, and K. Xiao. 2018. Contracting Arrangements and PPPs for Sustainable Development. Journal of Public Sector Economics. 42 (2). pp. 145-169.

Ahmad E., I. Neuweg, and N. Stern. (2018). China, the World and the Next Decade: Better Growth, Better Climate. London: Grantham Research Institute on Climate Change and the Environment and Centre for Climate Change Economics and Policy, London School of Economics and Political Science.

Ahmad, E. 2018a. Rebalancing in China: Fiscal Policies for Sustainable Growth. Singapore Economic Review. 63 (4). pp. 861-884.

Ahmad, E. 2018b. Governance Models and Policy Framework-Some Chinese Perspectives. Journal of Chinese Governance. 3 (2). pp. 129-157.

Ahmad, E. 2019. China: Options for Governance and Decentralization. For the World Bank and Chinese Academy of Fiscal Science. Beijing.

Ahmad, E. et al. 2019. Scaling Up Investment for Sustainable Urban Infrastructure: A Guide to National and Subnational Reform. Coalition for Urban Transitions and London School of Economics. https:// newclimateeconomy.report/workingpapers/wp-content/uploads/sites/5/2019/04/CUT2019_ Scaling_up_investment_for_sustainable_urban_infrastructure.pdf. 
Ahmad, E. and S. Colebrander. 2020. Financing a Sustainable and Inclusive Urban Transition in China. LSE/CUT/WRI Program on Financing Sustainable Urban Transitions in China and Mexico. https:// urbantransitions.global/en/publication/financing-a-sustainable-and-inclusive-urban-transitionin-china/\#.

Ahmad, E. et al. 2020. Designing Beneficial Property Taxation for Sustainable Development in ChinaEvidence from Six Cities Including Guangzhou. LSE/CUT/WRI Program on Financing Sustainable Urban Transitions in China and Mexico.

Bhattacharya, A. et al. 2016. Delivering on Sustainable Infrastructure for Better Development and Climate Change. Washington, DC: Brookings Institution.

Chen, Z., Z. He, and C. Liu. 2017. The Financing of Local Government in China: Stimulus Loan Wanes and Shadow Banking Waxes. National Bureau of Economic Research Working Paper Series No. 23598. (Revised October 2018).

Chen, H., R. Cui, Z. He, and K. Milbradt. 2017. Quantifying Liquidity and Default Risks of Corporate Bonds over the Business Cycle, The Review of Financial Studies, Volume 31, Issue 3, March 2018, pp. 852-897.

Liu, H. 2018. 3 Critical Battles China is Preparing to Fight. Speech for World Economic Forum, Davos. 24 January.

Luo, X. and N. Zhu. Forthcoming. Spatial Mobility and Regional Structural Transformation in China. LSE/CUT/WRI Program on Financing Sustainable Urban Transitions in China and Mexico.

Reschovsky, A. and Y. Yan. 2018. Measuring the Fiscal Health of Municipal Governments in Zhejiang Province. Beijing: Peking University Lincoln Institute.

Wang, W., A. Wu, and F. Ye. 2018. Land Use Reforms: Towards Sustainable Development in China. In Ahmad, E., M. Niu, and K. Xiao. Fiscal Policies for Sustainable Development in China-Rebalancing in Guangdong. New York: Springer.

Xiao, K. 2018. Managing Subnational Liability for Sustainable Development: A Case Study of Guangdong. In E. Ahmad, M. Niu, and K. Xiao. Fiscal Policies for Sustainable Development in ChinaRebalancing in Guangdong. New York: Springer.

Zhang, L. 2016. Rebalancing in China: Progress and Prospects. IMF Working Paper. 16-183. Washington, DC: IMF. 


\section{The Role of Local Governments in Driving High-Quality Growth in the People's Republic of China}

Over the past 25 years, the People's Republic of China (PRC) has gone through a long period of remarkable growth, lifting millions of people out of poverty. But this focus on growth has come at a cost, in particular in terms of environmental degradation, increasing socioeconomic and spatial inequalities and the building up of fiscal liabilities at the local government level.

Under the High-Quality Growth agenda, the PRC seeks to rebalance the economy by addressing those negative side effects, and local governments will have a key role to play in the implementation of that agenda. In this paper, some critical aspects of the fiscal and institutional environment, in which local governments operate, will be analyzed and proposals are offered for the strengthening of local government finances.

\section{About the Asian Development Bank}

ADB is committed to achieving a prosperous, inclusive, resilient, and sustainable Asia and the Pacific, while sustaining its efforts to eradicate extreme poverty. Established in 1966, it is owned by 68 members -49 from the region. Its main instruments for helping its developing member countries are policy dialogue, loans, equity investments, guarantees, grants, and technical assistance. 